\title{
Nature of "basal" and "reserve" cells in oviductal and cervical epithelium in man
}

\author{
WM PETERS
}

From the Department of Pathology, University of Leeds, Leeds

SUMMARY The epithelium of the human fallopian tube (oviduct) and cervix were studied by histological, immunohistological, and ultrastructural methods with a view to establishing the nature of the so called "basal" and "reserve" cells. The results indicated that the "basal" cells of the oviductal epithelia were $\mathrm{T}$ lymphocytes, with a predominance of T cytotoxic and suppressor cells. A more heterogeneous inflammatory cell population was present in cervical epithelium, although once again $\mathrm{T}$ cytotoxic and suppressor cells were the most numerous subtype. The intraepithelial inflammatory cells were quite distinct from the cells commonly referred to as "reserve" cells (reserve cell hyperplasia), which have epithelial characteristics.

The origin of the "reserve" cells is unclear, but they seem to arise within the epithelium. They probably represent an early sign of squamous metaplasia. The lymphoid tissue of the fallopian tube and endocervix shows similarities with that of the endometrium and mucosal associated lymphoid tissue in general.

The "basal" cells of rabbit oviductal and endocervical epithelium were studied ultrastructurally by Odor, ${ }^{1}$ who concluded that they were lymphocytes. Evidence for the migration of lymphocytes into oviductal epithelium has been reported in cattle, ${ }^{2}$ but in human tissue these cells have been said to resemble endometrial granulocytes or "K-cells". ${ }^{3}$ Furthermore, the "subcylindrical reserve cells of the endocervix" in human tissue have been reported as showing features similar to fibroblasts, ${ }^{4}$ and a derivation from Müllerian mesenchymal cells has been suggested. A standard textbook of gynaecological pathology, however, states that the "subcolumnar reserve cells" of the endocervix have general fine structural characteristics similar to the basal cells of mature squamous portio epithelium. ${ }^{5}$

This study was performed to establish the histological, immunohistological, and ultrastructural characteristics of "basal" and "reserve" cells in oviductal and endocervical epithelium with a view to establishing their true nature.

\section{Material and methods}

Segments from the ampullary part of normal fallopian tubes were obtained from patients who had undergone sterilisation or incidental salpingectomy at the

Accepted for publication 2 December 1985 time of hysterectomy.

Cervical tissue was obtained from the uteri of patients who had undergone a hysterectomy for fibroids, dysmenorrhoea, or dysfunctional uterine bleeding. The blocks were taken to include ectocervical squamous epithelium, the squamocolumnar junction, and the endocervix. None of the patients had clinical cervical disease or any abnormality of the cervix visible to the naked eye.

All of the tissue was received fresh within four hours of operation.

\section{HISTOLOGY}

Tissue from six fallopian tubes and fifteen cervices was fixed in $10 \%$ neutral buffered formalin for $24-36$ hours. The blocks were routinely processed to paraffin wax, and 4 micron sections were cut and stained with haematoxylin and eosin.

\section{IMMUNOHISTOLOGY}

Immunohistology was performed on both paraffin embedded tissue and on tissue snap frozen in liquid nitrogen.

\section{Paraffin immunohistology}

Examination of the sections stained with haematoxylin and eosin cut from the 15 blocks of cervix showed three cases in which areas of "reserve" cell hyperplasia could easily be found. These three cases, 
three cervices in which "reserve" cell hyperplasia was not prominent, and the six fallopian tubes were selected for immunohistological staining.

Sections were cut at 4 microns, floated on to glass slides, dewaxed in xylene, and taken to water via absolute alcohol. They were stained for leucocyte common antigen, epithelial membrane antigen, keratin, and lysosyme using a two stage indirect immunoperoxidase technique. The antibodies were obtained from Dakopatts, High Wycombe. Endogenous peroxidase activity was blocked by incubating the slides with $3 \%$ hydrogen peroxide in methanol for 30 minutes. The monoclonal primary antisera to leucocyte common antigen and epithelial membrane antigen were applied to the sections in a $1 / 10$ dilution and incubated overnight. The polyclonal antisera to keratin and lysosyme were applied to the sections in a $1 / 100$ dilution for one hour following trypsinisation $(0.1 \%$ trypsin in Tris buffer at $\mathrm{pH} 7.8$ for 35 minutes at $37^{\circ} \mathrm{C}$ ). The sections were then washed and incubated with $1 / 30$ peroxidase conjugated rabbit antimouse immunoglobulin (leucocyte common antigen and epithelial membrane antigen) or peroxidase conjugated swine antirabbit immunoglobulin (keratin and lysosyme) for 30 minutes. The peroxidase conjugates were obtained from Dakopatts, High Wycombe. Finally, the sections were washed, developed in diaminobenzidine and hydrogen peroxide, and counterstained with haematoxylin.

\section{Frozen section immunohistology}

Samples from three fallopian tubes and three cervices were selected at random and snap frozen in liquid nitrogen. Cryostat sections were cut at 8 microns, freeze dried overnight, and acetone fixed for 20 minutes at room temperature. The sections were rehydrated in Tris buffer ( $\mathrm{pH}$ 7.6) and stained using a two stage immunoperoxidase technique. The primary antisera listed in the Table were applied to the sections for 30 minutes. The sections were washed twice in Tris buffer (pH 7.6) and incubated with either 1/50 Dakopatts peroxidase conjugated rabbit antimouse immu-

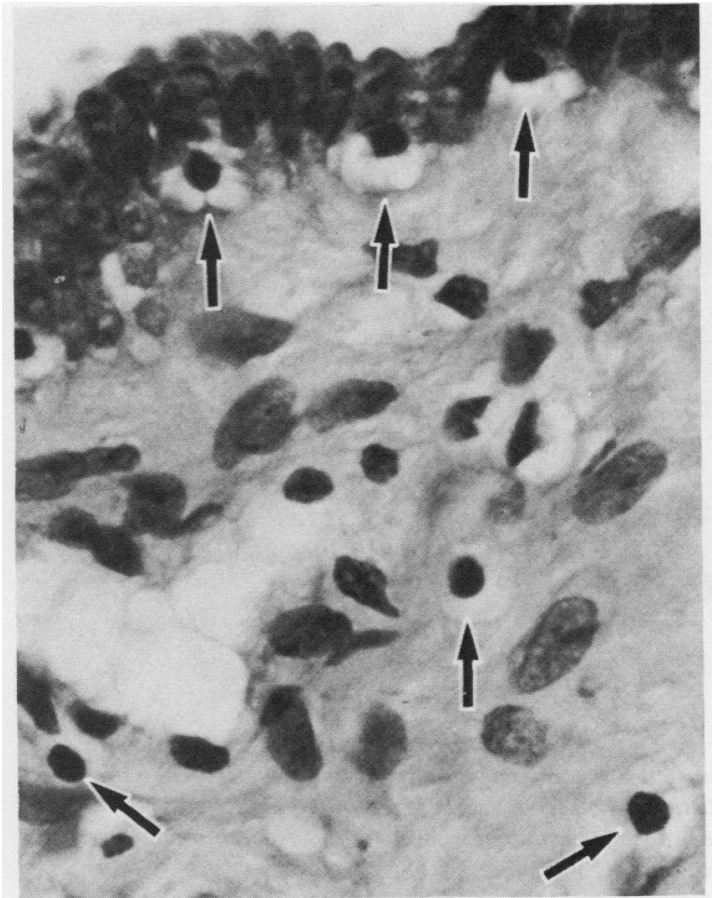

Fig. 1 "Basal" cells in oviductal epithelium have round to oval nuclei and a perinuclear halo (arrows). Similar cells are present in stroma. (Haematoxylin and eosin.) $\times 500$.

noglobulin (monoclonal antibodies) or peroxidase conjugated swine antirabbit immunoglobulin (polyclonal antibodies) for 30 minutes. After washing the sections were developed in diaminobenzidine and hydrogen peroxide with amidazole as catalyst. Finally, the sections were washed, mordanted with $0.5 \%$ copper sulphate in isotonic saline, and counterstained with methyl green.

\section{ELECTRON MICROSCOPY}

Tissue from two of the fallopian tubes was fixed in $3 \%$

Antibodies used for cryostat immunohistology

\begin{tabular}{|c|c|c|c|c|c|}
\hline Antibody & Type & Specificity & Source & Dilution & \\
\hline $\begin{array}{l}\text { OKT4 } \\
\text { OKT8 } \\
\text { OKT11 } \\
\text { OKM5 } \\
\text { Dako Pan B } \\
\kappa \\
\lambda \\
\text { IgG } \\
\text { IgA } \\
\text { IgM } \\
\text { IgD }\end{array}$ & $\begin{array}{l}\text { Monoclonal } \\
\text { Monoclonal } \\
\text { Monoclonal } \\
\text { Monoclonal } \\
\text { Monoclonal } \\
\text { Monoclonal } \\
\text { Monoclonal } \\
\text { Monoclonal } \\
\text { Polyclonal } \\
\text { Polyclonal } \\
\text { Polyclonal }\end{array}$ & $\begin{array}{l}\text { T helper lymphocytes (some cross } \\
\text { reactivity with monocytes) } \\
\text { T cytotoxic and suppressor } \\
\text { T lymphocytes } \\
\text { Macrophages } \\
\text { B lymphocytes } \\
\kappa \text { light chain } \\
\lambda \text { light chain } \\
\text { IgG heavy chain } \\
\text { IgA heavy chain } \\
\text { IgM heavy chain } \\
\text { IgD heavy chain }\end{array}$ & \} & $\begin{array}{l}\text { Ortho Diagnostic Systems, } \\
\text { High Wycombe } \\
\text { Dakopatts, High Wycombe } \\
\text { Unipath, Bedford } \\
\text { Dakopatts, High Wycombe }\end{array}$ & $\begin{array}{l}1 / 50 \\
1 / 50 \\
1 / 50 \\
1 / 64 \\
1 / 40 \\
1 / 500 \\
1 / 500 \\
1 / 1000 \\
1 / 600 \\
1 / 600 \\
1 / 1000\end{array}$ \\
\hline
\end{tabular}




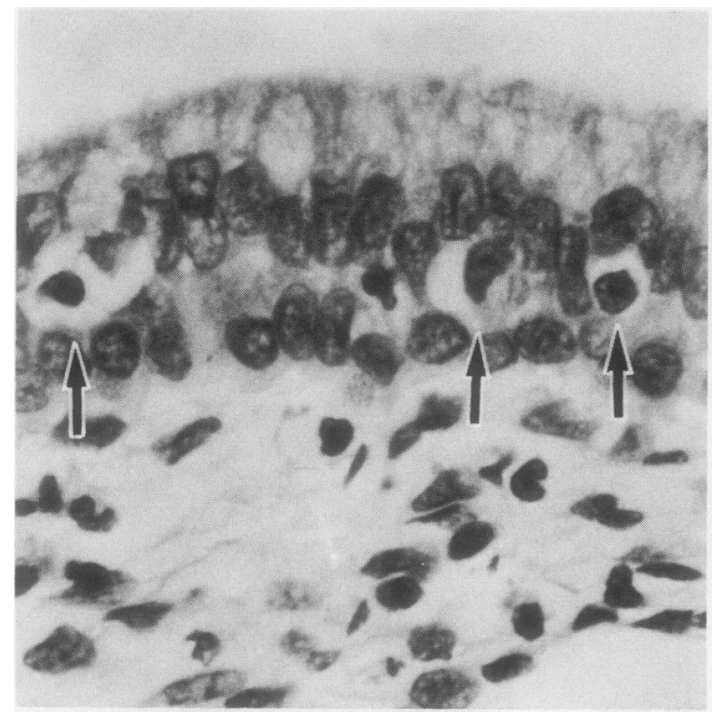

Fig. 2 Cells resembling oviductal "basal" cells are also present in endocervical epithelium (arrows). They are easily distinguished from single layer of cuboidal "reserve" cells seen beneath columnar epithelium. (Haematoxylin and eosin.). $\times 500$.

buffered gluteraldehyde for three ìours, washed overnight in phosphate buffered saline ( $\mathrm{pH} 7.35)$, and then fixed in osmium tetroxide for one hour. The tissue was dehydrated in alcohol and embedded in Polarbed and Araldite. Ultrathin sections were stained with uranyl acetate and lead citrate and viewed in a Jeol 1200EX electron microscope.

In view of the focal nature of "reserve" cell hyperplasia in the cervix prospective random sampling into gluteraldehyde was considered unlikely to be successful. Formalin fixed tissue from two of the cases identified as exhibiting widespread "reserve" cell hyperplasia was therefore sampled retrospectively and processed for electron microscopy as above.

\section{Results}

\section{HISTOLOGY}

The "basal" cells of the oviductal epithelium usually had small, dark, round to oval nuclei and a perinuclear "halo" (Fig. 1). A minority of these cells had larger and more irregularly contoured nuclei. Similar cells were present in cervical squamous and columnar epithelium, and I use the term "basal" cell exclusively to denote cells with this morphology. The layer of small cuboidal cells seen beneath the columnar endocervical mucinous epithelium in three of the cervices was easy to distinguish from "basal" cells (Fig. 2), and the term "reserve" cell is used exclusively for this type of cell.

\section{Paraffin immunohistology}

The luminal border of the oviductal epithelium was strongly positive for epithelial membrane antigen, with a minor degree of patchy cytoplasmic positivity. The "basal" cells and stromal cells did not stain for epithelial membrane antigen (Fig. 3). The tubal epithelium also exhibited patchy luminal and cytoplasmic positivity for keratin, and once again the stroma was negative. The "basal" cells were usually positive for leucocyte common antigen, and similar positive cells were scattered throughout the stroma. Lysosyme positive cells were present in the stroma, and in one case very occasional lysosyme positive cells were present within the oviductal epithelium. The number of lysosyme positive cells varied, but in all cases they were outnumbered by leucocyte common antigen positive cells. The lysosyme positive cells were mainly granulocytes, with a few histiocytes admixed. The tubal epithelial cells, fibroblasts, and smooth muscle cells were negative for leucocyte common antigen and lysosyme.

The cervical squamous epithelium stained positively for epithelial membrane antigen and keratin but was negative for leucocyte common antigen and lysosyme. The pattern of staining varied with a tendency for epithelial membrane antigen to stain the surface and keratin the basal layers. Staining was usually strongest in transitional zone or metaplastic squamous epithelium. The columnar mucinous endocervical epithelium was also positive for epithelial membrane antigen and keratin and negative for leuco-

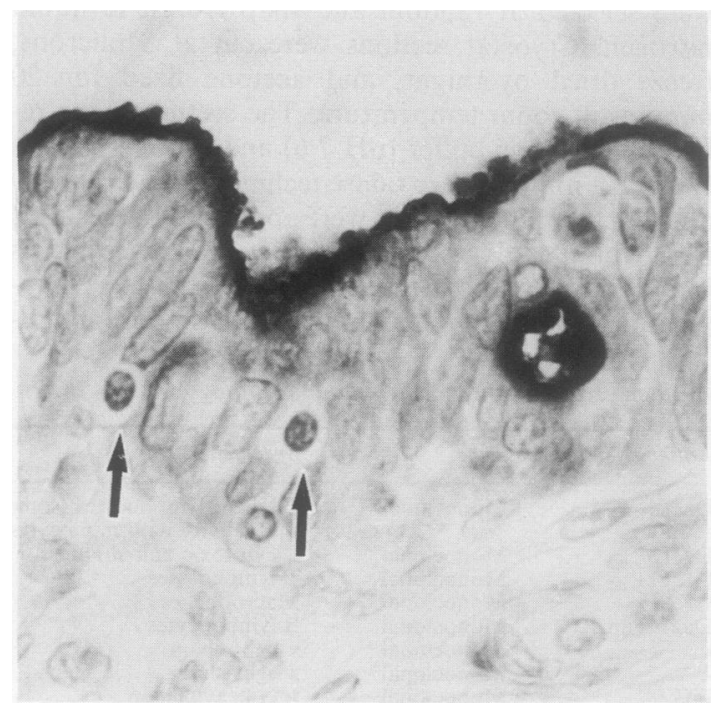

Fig. 3 Oviductal epithelium shows strong luminal positivity for epithelial membrane antigen. "Basal" cells (arrows) are negative. (Indirect immunoperoxidase.) $\times 500$. 


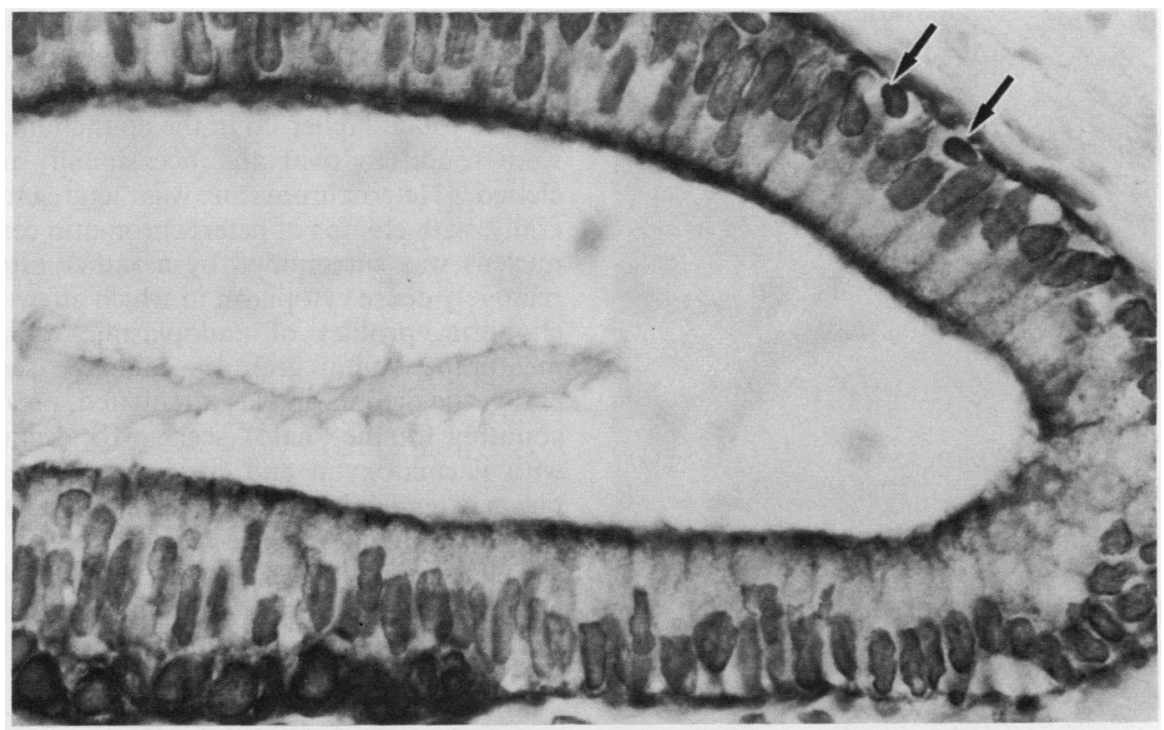

Fig. 4 Subcolumnar "reserve" cells seen at bottom left of this endocervical crypt are strongly positive for keratin. Columnar cells show some luminal positivity, but "basal" cells (arrows) are negative. (Indirect immunoperoxidase.) $\times 500$.

cyte common antigen and lysosyme. Positivity was again patchy, with both antibodies tending to stain the surface of the cells, especially in areas of "reserve" cell hyperplasia. The "reserve" cells showed weak

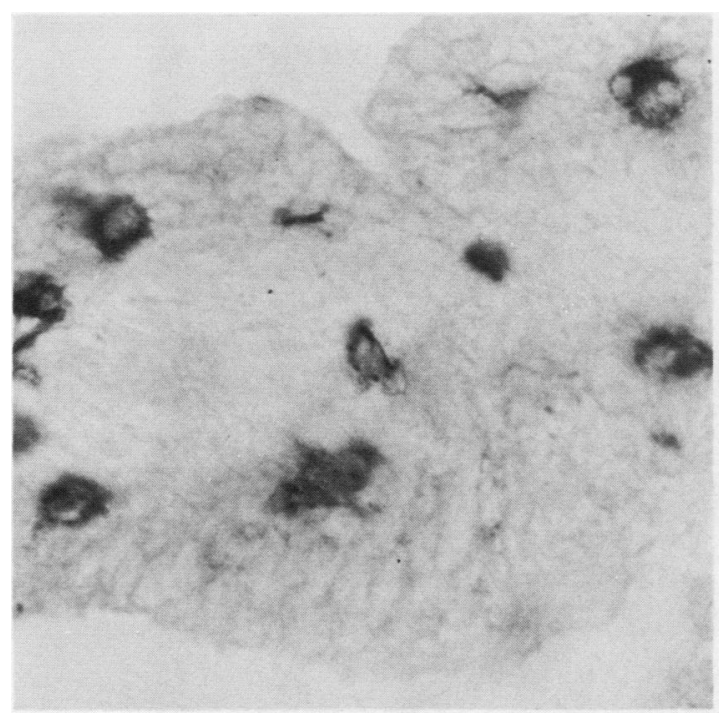

Fig. 5 Most intraepithelial "basal" cells in oviduct are OKT8 positive. Staining reaction is indistinguishable from that of stromal lymphocytes. (Indirect immunoperoxidase.) $\times 500$. patchy positivity for epithelial membrane antigen but were strongly positive for keratin (Fig. 4). They were negative for leucocyte common antigen and lysosyme. The "basal" cells were positive for leucocyte common antigen, or, less commonly lysosyme, but were negative for epithelial membrane antigen and keratin. There were leucocyte common antigen and lysosyme positive cells within the stroma, and these seemed to be lymphocytes, granulocytes, and macrophages.

\section{Frozen section immunohistology}

Most of the "basal" cells of the oviductal epithelium were OKT8 positive (Fig. 5). A lesser number of OKT4 positive cells were also present, comprising roughly $15-20 \%$ of the T lymphocyte population. A qualitatively and quantitatively similar lymphoid population was present in the stroma. Very occasional OKM 5 or Pan B positive cells were seen in the stroma, but none was detected in the epithelium. The B lymphocytes were usually IgA positive.

The inflammatory cell population of the cervix was comparatively heterogeneous. Most of the "basal" cells in the squamous epithelium, the columnar epithelium, and the stroma were once again OKT8 positive (Fig. 6). OKT4 positive cells were present in proportionally greater numbers than in the fallopian tube, comprising about $30-40 \%$ of the total $\mathrm{T}$ lymphocyte population. Pan B positive lymphocytes (and plasma cells) were present in the stroma but were only rarely seen in the epithelium. Cells positively stained 


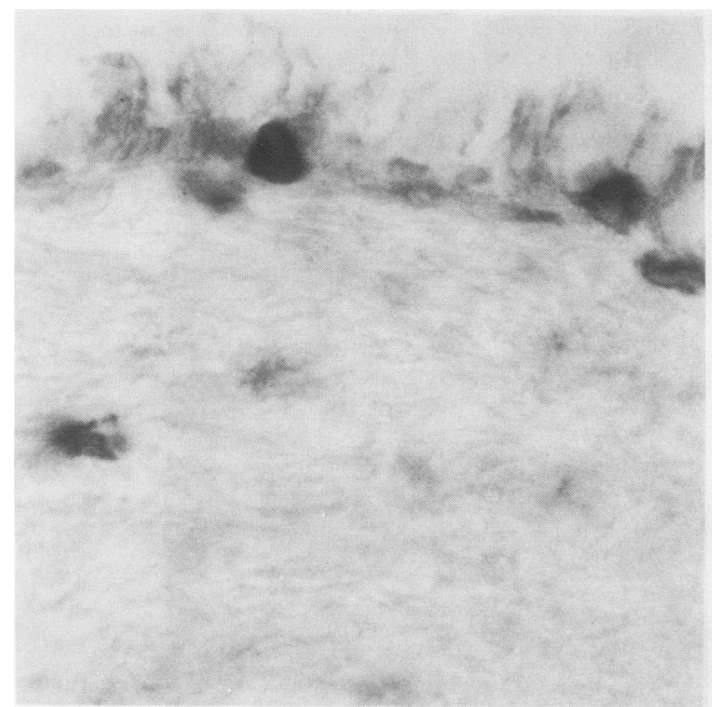

Fig. 6 Most intraepithelial "basal" cells in cervix are OKT8 positive, and once again staining reaction is strikingly similar to that of stromal lymphocytes. (Indirect immunoperoxidase.) $\times 500$.

for each of the light and heavy chains were found, IgM positive cells being slightly predominant. OKM5 positive cells were less common than T or B cells and were present in the stroma and occasionally within the epithelium.

\section{ELECTRON MICROSCOPY}

The "basal" cells in the oviductal epithelium were usually located close to the basal lamina but could also be found higher up in the epithelium. The nuclei were round to oval and occasionally indented or clefted. Heterochromatin was aggregated peripherally, with clumps of heterochromatin centrally. The nucleus was surrounded by a rather ragged rim of relatively dense cytoplasm in which a few small mitochondria, profiles of endoplasmic reticulum, and membrane bound granules could be seen. Peripherally, the cytoplasm was attenuated, presumably accounting for the "halo" seen in the sections stained with haematoxylin and eosin. Sometimes the cytoplasm extended between adjacent epithelial cells (Fig. 7), but no junctions were seen.

Cells similar to "basal" cells were also present within the endocervical columnar epithelium. They were clearly different to the subcolumnar "reserve" cells, which had larger more convoluted nuclei and relatively homogeneous cytoplasm. The "reserve" cells had quite prominent cytoplasmic filaments, and in some of the cells these were morphologically indistinguishable from tonofilaments. Furthermore, the cells were joined to their neighbours by scant desmosomes (Fig. 8). Although occasional discontinuities in the basal lamina were seen, these seemed to be the result of inflammatory cells migrating into the epithelium or plane of section artefact. No evidence of fibroblast like cells migrating across the basal lamina to form the "reserve" cell layer was seen.

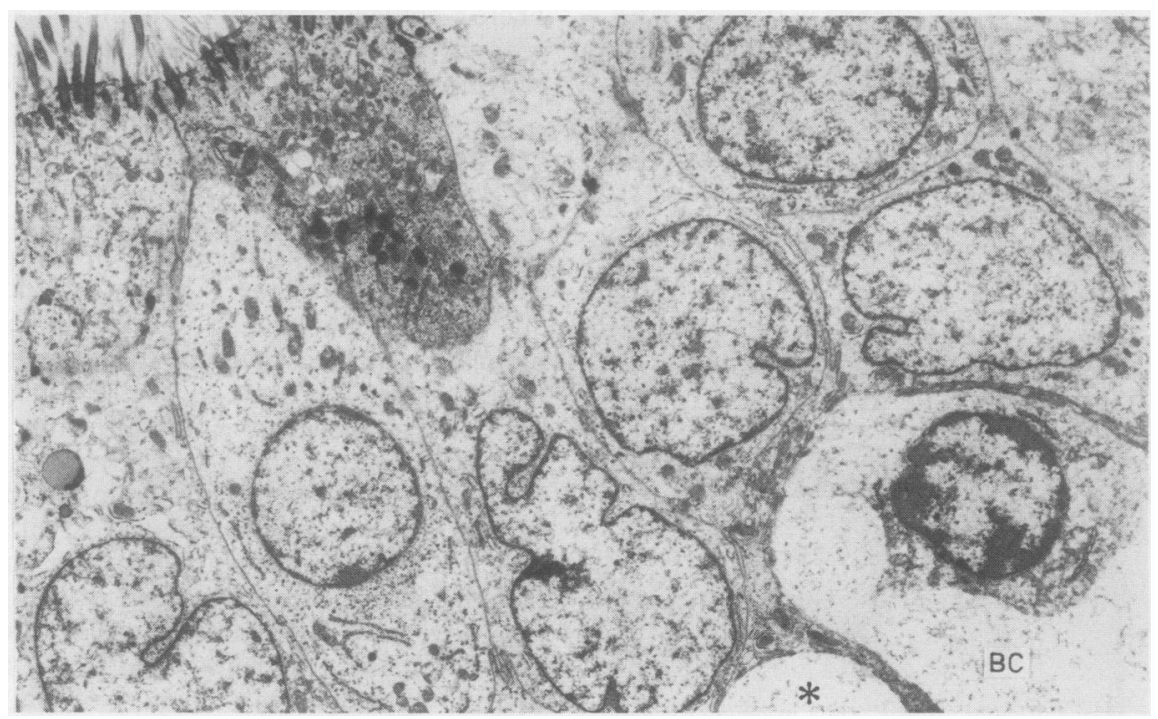

Fig. 7 "Basal" cell (BC) in human oviductal epithelium. Halo seen in paraffin sections seems to be due to peripheral rarefaction of cytoplasm. Cytoplasm of "basal" cells sometimes interdigitates with that of epithelial cells (*). (Uranyl acetate and lead citrate.) $\times 6000$. 


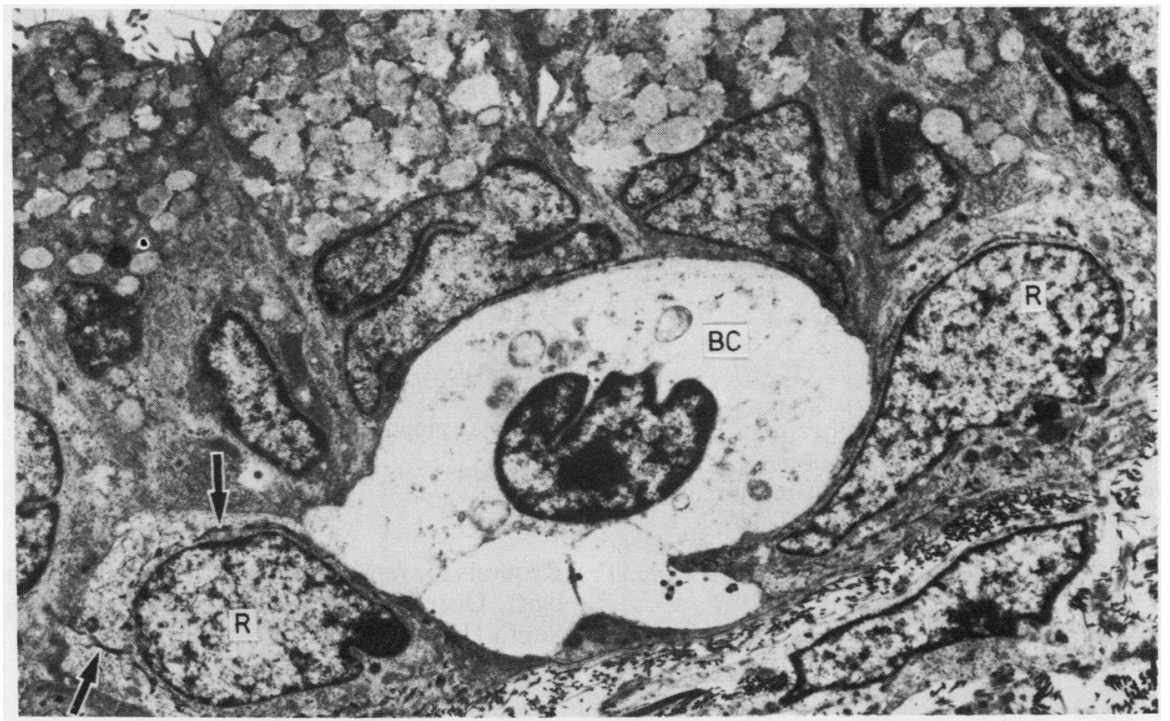

Fig. 8 "Basal" cell (BC) in human endocervical epithelium. It is clearly different to "reserve" cells $(R)$, which have epithelial characteristics including bundles of cytoplasmic filaments (arrows). (Uranyl acetate and lead citrate.) $\times 3000$.

\section{Discussion}

The results indicate that the "basal" cells of human oviductal epithelium are predominantly $T$ lymphocytes, with a cytotoxic and suppressor (OKT8) to helper (OKT4) cell ratio of about 6:1 in the three cases examined. The presence of a similar lymphocyte population in the stroma suggests that stromal lymphocytes migrate across the basal lamina into the epithelium, presumably in a manner analagous to that postulated in the endometrium. ${ }^{6}$ Although a variable number of granulocytes were found in the stroma, they seemed to make a minimal contribution to the intraepithelial inflammatory cell population under physiological conditions. The suggestion that they are "granulocyte-like" 3 is therefore not supported by the findings of this study.

Most of the intraepithelial inflammatory cells ("basal" cells) found within the cervical squamous and columnar epithelium were also $T$ lymphocytes, but B lymphocytes, granulocytes, and macrophages were also found. The cytotoxic and suppressor (OKT8) to helper (OKT4) cell ratio was more variable than that found in the oviduct but was generally about 2:1 or 3:1. Possibly, cross reactivity of OKT4 with monocytes and macrophages may, in part, be responsible for the apparent increase in the proportion of helper cells in the cervix.

The finding that the "basal" cells of the oviductal and cervical epithelia were $T$ cytotoxic and suppressor lymphocytes is in keeping with reported nature of the intraepithelial lymphocytes of the endometrium and other mucosal sites. ${ }^{6}$ The possible roles of the mucosal associated lymphocyte tissue have been discussed elsewhere. ${ }^{26}{ }^{7}$ I would, however, like to draw attention to the link between $T$ lymphocytes and apoptosis and the loss of epithelial cells by apoptosis. ${ }^{8}$ Although I have not found any morphological evidence that the intraepithelial T lymphocytes induce apoptosis in the oviduct or cervix, the possibility that they have a role in immune surveillance and the elimination of abnormal cells merits consideration. ${ }^{9}$

Subcolumnar "reserve" cells were found in the cervix but not in the oviduct. They have epithelial characteristics whether examined by light microscopy, immunohistochemistry, or electron microscopy. They seem to differ from the intraepithelial lymphocytes reported in rabbit endocervical tissue by Odor, ${ }^{1}$ which are presumably analagous to the intraepithelial lymphocytes in man. Odor does not seem to have studied subcolumnar "reserve" cells as defined in this paper.

The origin of subcolumnar "reserve" cells is uncertain, ${ }^{5}$ but I could find no evidence to support the contention that they are fibroblast like cells derived from the Müllerian mesenchyme. ${ }^{4}$ There were occasional breaks in the epithelial basal lamina, but no fibroblast like cells were seen in the epithelium, and no epithelial like cells were seen in the stroma. It would seem more likely that they arise within the epithelium, either from an inconspicuous stem cell population or 
by metaplasia of columnar cells. Whatever their origin, they resemble the basal layer of squamous epithelium, which suggests that they are an early manifestation of squamous metaplasia.

I thank $\mathbf{P}$ Jackson, $\mathbf{P}$ Connor, C Butler, DA Robinson, P Walsh, and S Toms for technical help, and the Yorkshire Regional Cancer Organisation for the antibody studies on frozen tissue.

\section{References}

${ }^{1}$ Odor DL. The question of "basal" cells in oviductal and endocervical epithelium. Fertil Steril 1974;25:1047-62.

${ }^{2}$ DuBois JA, Wordinger RJ, Dickey JF. Tissue concentrations of mast cells and lymphocytes of the bovine uterine tube (oviduct) during the estrous cycle. Am J Vet Res 1980;41:806-9.

${ }^{3}$ Van Bogaert L-J, Maldague P, Staquet JP. The percentage of granulocyte-like cells in human oviduct epithelium. Br J Obstet Gynaecol 1978;85:373-5.

${ }^{4}$ Minh H-N, Lecomte D, Smadja A, Orcel L, Coupez F. A hypoth- esis on the origin of the subcylindrical reserve cells of the endocervix. Path Res Pract 1981;172:88-98.

${ }^{5}$ Ferenczy A. Anatomy and histology of the cervix. In: Blaustein A, ed. Pathology of the female genital tract. 2nd ed. New York Springer-Verlag, 1982:119-35.

${ }^{6}$ Morris H, Edwards J, Tiltman A, Emms M. Endometrial lymphoid tissue: an immunohistological study. J Clin Pathol 1985; 38:644-52.

${ }^{7}$ Bienenstock J, Befus AD. Mucosal immunology. Immunology 1980;41:249-70.

${ }^{8}$ Kerr JFR, Bishop CJ, Searle J. Apoptosis. In: Anthony PP, MacSween RNM, eds. Recent advances in histopathology. Vol. 12. Edinburgh: Churchill Livingstone, 1984:1-15.

${ }^{9}$ Tagliabue A, Befus AD, Clark DA, Bienenstock J. Characteristics of natural killer cells in the murine intestinal epithelium and lamina propria. J Exp Med 1982;155:1785-96.

Requests for reprints to: Dr WM Peters, Consultant Pathologist, District General Hospital, Scartho Road, Grimsby, South Humberside DN33 2BA, England. 